\title{
THE NEUROLOGICAL FACE OF CELIAC DISEASE
}

\author{
Sedat IȘIKAY ${ }^{1}$ and Halil KOCAMAZ²
}

Received 15/9/2014 Accepted 5/11/2014

\begin{abstract}
Background - Several neurological disorders have also been widely described in celiac disease patients. Objective - The aim of this study was to determine the incidence of accompanying different neurologic manifestations in children with celiac disease at the time of diagnosis and to discuss these manifestations in the light of the recent literature. Methods - This prospective cross sectional study included 297 children diagnosed with celiac disease. The medical records of all patients were reviewed. Results In neurological evaluation, totally $40(13.5 \%)$ of the 297 celiac patients had a neurological finding including headache, epilepsy, migraine, mental retardation, breath holding spells, ataxia, cerebral palsy, attention deficit hyperactivity disorder, Down syndrome and Turner syndrome in order of frequency. There was not any significant difference between the laboratory data of the patients with and without neurological manifestations. However; type 3a biopsy was statistically significantly more common among patients without neurological manifestations, while type $3 \mathrm{~b}$ biopsy was statistically significantly more common among patients with neurological manifestations. Conclusion - It is important to keep in mind that in clinical course of celiac disease different neurological manifestations may be reported.
\end{abstract}

HEADINGS - Celiac disease. Neurologic manifestations. Child.

\section{INTRODUCTION}

Celiac disease (CD) is an autoimmune inflammatory condition mainly distressing proximal small intestine with a prevalence of $0.7 \%-2.0 \%$ in general population $^{(21)}$. It is an immune mediated disease affecting genetically susceptible cases who express the human leucocyte antigen (HLA) class II molecules DQ2 or DQ8 ${ }^{(11)}$. This is a disease of malabsorption and the main symptoms include postprandial bloating, steatorrhea, and weight loss. In about 10\%-22\% of patients with celiac disease; neurological symptoms are reported including ataxia, neuropathy, vestibular dysfunction, seizures, migraine, and headache ${ }^{(3,22,24)}$.

The aim of this study was to determine the incidence of accompanying different neurologic manifestations in children with $\mathrm{CD}$ at the time of diagnosis and to discuss these manifestations in the light of the recent literature. Also we aimed to compare some laboratory data and biopsy findings of celiac disease patients with and without neurological manifestations. Neurological findings of Celiac disease constitute a wide range and we aimed to increase the awareness of the neurological face of the celiac disease.

\section{METHODS}

The study was carried out in Pediatric Neurology and Gastroenterology Departments of Gaziantep Children's Hospital, Gaziantep, Turkey in between October 2012 and June 2014. The study was approved by local Ethical Committee and informed consent was obtained from the parents of all patients. All patients approving to participate in the study were included.

Diagnosis of CD was made clinically, based on the class IgA anti-tissue transglutaminase (anti-tTG) levels and multiple biopsy (at least 1 from bulb and 4 from the second part of the duodenum) findings of an upper gastrointestinal endoscopy with a flexible endoscope. The biopsy results of all participants were recorded according to Marsh classification (Figure 1) ${ }^{(16)}$. A single pathologist reported the biopsy results. Gender, age, weight and height of all subjects at the diagnosis of $\mathrm{CD}$ were recorded.

\section{Laboratory tests}

All of the subjects were examined after an overnight fasting of 8 hours. All participants' hemoglobin, mean corpuscular volume (MCV), red cell distribution

\footnotetext{
Declared conflict of interest of all authors: non

Disclosure of funding: no funding received

'Department of Pediatric Neurology, Faculty of Medicine, Sutcu Imam University, Kahramanmaras, Turkey; 2Department of Pediatric Gastroenterology, Gaziantep Children's Hospital, Gaziantep, Turkey.

Correspondence: Sedat Ișikay. Department of Pediatric Neurology, Faculty of Medicine, Sutcu Imam University, Kahramanmaras, Turkey. E-mail: dr.sedatisikay@mynet.com
} 


\section{Marsh grade}

\section{$0 \quad$ Normal mucosa}

1 Increased number of intraepithelial lymphocytes, usually exceeding 20 per 100 enterocytes

2 Proliferation of the crypts of liberkuhn

3 Variable villous atrophy

3a Partial villous atrophy

3b Subtotal villous atrophy

3c Total villous atrophy

4 Hypoplasia of the small bowel architecture

FIGURE 1. Marsh grading

width (RDW), platelet count, iron, iron binding capacity, ferritin, vitamin B12 and folic acid levels, liver function tests [including alanine amino transferase (ALT), aspartate amino transferase (AST), and alkaline phosphatase (ALP) levels], albumin, sedimentation, calcium, phosphorus, parathyroid hormone and vitamin D levels, thyroid stimulating hormone (TSH), and free thyroxin levels were studied using the standard methods recommended by the manufacturer. The results of DEXA for osteoporosis screening were also recorded.

\section{Statistical analysis}

All analyses were performed with the Statistical Package for Social Sciences (SPSS) for Windows 17.0 program. Comparisons of demographic features of groups were performed with Pearson $\chi^{2}$ tests while comparisons of laboratory data were made using two-tailed Student's $t$-test. Results were expressed as mean \pm S.D. The $P<0.05$ was considered as statistically significant.

\section{RESULTS}

This is a prospective, cross sectional study. Totally $297 \mathrm{pa}-$ tients, with a mean age of $10.04 \pm 4.11$ (range: $1-18$ years) years, diagnosed with celiac disease are included in the study. Among those 179 were female and 118 were male. When those cases were evaluated; 130 had chronic diarrhea, 50 had constipation; 133 had bloating sensation, 32 had abdominal distention, 174 had growth retardation and 83 had short stature. Stomach ache was reported in 166 cases while 56 cases had vomiting. Hypothyroidism was present in seven cases, osteoporosis was reported in 18 cases, and osteopenia was reported in 17 cases. Anemia was reported in 120 cases and all of them were iron deficiency anemia. The mean symptom starting age of the participants was $64.2 \pm 42.3$ months. In neurological evaluation of patients headache was reported in $29(9.7 \%)$ cases and migraine was present in 13(4.4\%) cases. Epilepsy was seen in $16(5.4 \%)$ cases and among those 10 had generalized seizures while 6 had partial convulsions. Breath holding spells was present in $4(1.3 \%)$ cases. Mental retardation was reported in $12(4.0 \%)$ cases, cerebral palsy was present in $2(0.7 \%)$ cases, and attention deficit hyperactivity disorder (ADHD) was reported in $2(0.7 \%)$ cases. Down syndrome was reported in 1 $(0.3 \%)$ case and Turner syndrome was present in $1(0.3 \%)$ case. Ataxia was reported in $2(0.7 \%)$ cases. In conclusion, totally 40 $(13.5 \%)$ of the 297 celiac patients had a neurological finding.
The comparison of general characteristics and laboratory data of celiac patients with and without neurological findings are summarized in Table 1. There was not any significant difference between the laboratory data of the patients with and without neurological manifestations.

Among the patients without neurological problems; 3 $(1.2 \%)$ were having type $1,7(2.7 \%)$ were having type 2,174 $(67.7 \%)$ were having type $3 a, 52(20.2 \%)$ were having type $3 b$ and $19(7.4 \%)$ were having type $3 \mathrm{c} \mathrm{CD}$ according to Marsh classification in their duodenum biopsies. On the other hand, among patients with neurological manifestations; 16 (40.0\%) were having type $3 \mathrm{a}, 18(45.0 \%)$ were having type $3 \mathrm{~b}$ and 6 $(15.0 \%)$ were having type $3 \mathrm{c} \mathrm{CD}$ in their duodenum biopsies and type 1 or 2 were not present. In that aspect; type 3a biopsy was statistically significantly more common among

TABLE 1. General characteristics and laboratory data of celiac patients with and without neurological findings

\begin{tabular}{|c|c|c|c|}
\hline & $\begin{array}{l}\text { Patients without } \\
\text { any neurological } \\
\text { manifestations } \\
(\mathrm{n}=257)\end{array}$ & $\begin{array}{l}\text { Patients with } \\
\text { neurological } \\
\text { manifestations } \\
\quad(\mathrm{n}=40)\end{array}$ & $P$ \\
\hline Age (years) & $10.05 \pm 4.12$ & $10.02 \pm 4.11$ & 0.96 \\
\hline Height ( $\mathrm{Z}$ score) & $-1.43 \pm 1.30$ & $-0.97 \pm 1.48$ & 0.31 \\
\hline Weight (Z score) & $-0.30 \pm 1.07$ & $-0.79 \pm 1.31$ & 0.23 \\
\hline Hemoglobin & $12.57 \pm 1.33$ & $12.46 \pm 1.16$ & 0.71 \\
\hline $\mathrm{MCV}$ & $79.59 \pm 6.49$ & $79.18 \pm 6.46$ & 0.80 \\
\hline RDW & $14.65 \pm 2.31$ & $16.15 \pm 3.22$ & 0.11 \\
\hline Platelet count & $307.21 \pm 79.38$ & $292.87 \pm 79.30$ & 0.49 \\
\hline Iron & $60.40 \pm 34.81$ & $59.32 \pm 39.44$ & 0.14 \\
\hline Iron binding capacity & $327.27 \pm 73.50$ & $324.23 \pm 74.07$ & 0.21 \\
\hline Ferritin & $13.26 \pm 12.28$ & $15.25 \pm 18.79$ & 0.33 \\
\hline Vitamin B12 & $354.22 \pm 141.20$ & $370.35 \pm 124.22$ & 0.54 \\
\hline Folic acid & $8.86 \pm 3.62$ & $8.74 \pm 4.07$ & 0.87 \\
\hline AST & $32.37 \pm 8.25$ & $35.41 \pm 11.99$ & 0.32 \\
\hline ALT & $26.32 \pm 9.39$ & $24.29 \pm 8.31$ & 0.40 \\
\hline ALP & $216.73 \pm 76.65$ & $184.60 \pm 50.66$ & 0.22 \\
\hline Albumin & $4.10 \pm 0.31$ & $4.29 \pm 0.33$ & 0.14 \\
\hline Sedimentation & $14.50 \pm 12.64$ & $14.84 \pm 11.79$ & 0.91 \\
\hline Calcium & $9.38 \pm 0.44$ & $9.37 \pm 0.48$ & 0.92 \\
\hline Phosphorus & $4.26 \pm 0.40$ & $4.56 \pm 0.45$ & 0.41 \\
\hline Parathyroid hormone & $60.46 \pm 50.74$ & $54.25 \pm 20.35$ & 0.14 \\
\hline Vitamin D & $33.46 \pm 8.48$ & $25.75 \pm 14.49$ & 0.58 \\
\hline TSH & $2.60 \pm 2.35$ & $1.85 \pm 0.58$ & 0.11 \\
\hline Free thyroxine & $1.19 \pm 1.80$ & $1.29 \pm 1.62$ & 0.61 \\
\hline
\end{tabular}

MCV: mean corpuscular volume, RDW: red cell distribution with, AST: aspartate amino transferase, ALT: alanine amino transferase, ALP: alkaline phosphatase, TSH: thyroid stimulating hormone. The data are expressed as mean \pm S.D. 
patients without neurological manifestations, while type $3 \mathrm{~b}$ biopsy was statistically significantly more common among patients with neurological manifestations $(P<0.001)$. The comparison of pathological type of $\mathrm{CD}$ of those patients is shown in Figure 2.

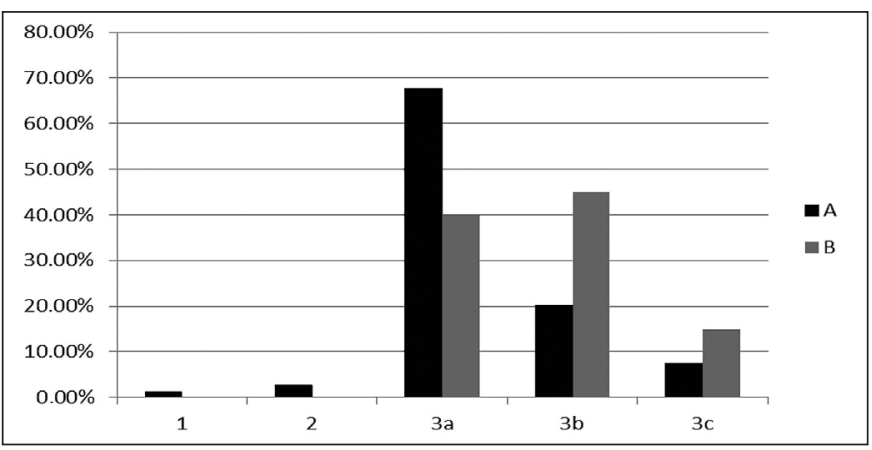

FIGURE 2. Comparison of the pathological types of celiac disease among groups, A: neurological manifestation absent, B: neurological manifestation present.

\section{DISCUSSION}

In this study we have studied on 297 children with CD and reported that $40(13.5 \%)$ of those children have a type of neurologic manifestation. The neurologic signs reported in that study in order of frequency were headache, epileptic seizures, migraine, mental retardation, breath holding spells, ataxia, cerebral palsy, attention deficit hyperactivity disorder, Down syndrome and Turner syndrome. To the best of our knowledge this is the first study in literature comparing laboratory and biopsy findings of celiac patients with and without any neurological findings. Interestingly, although there was not any difference between two groups in regards to laboratory findings; Marsh type $3 \mathrm{~b}$ pathology was more common among patients with neurological manifestations.

In a recent study, Diaconu et al. ${ }^{\left({ }^{(8)}\right.}$ monitored 48 children with the diagnosis of $\mathrm{CD}$ and they reported that $16(33.3 \%)$ presented one or more neurologic symptoms as the onset manifestation of CD. The neurologic signs reported in that study in order of frequency were: headache/migraine, attention-deficit/hyperactivity disorder, epileptic seizures, mental retardation, and cerebellar ataxia and behavior disorders. We have determined the headache $(9.7 \%)$ as the most common neurologic manifestation in patients with celiac disease. Dimitrova et al. ${ }^{(9)}$ reported the prevalence of chronic headache as $30 \%$ in celiac disease patients ${ }^{(9)}$. Similarly Lionetti et al. ${ }^{(14)}$ determined that $24.8 \%$ of patients with CD complained of headaches before the diagnosis of CD as compared with $8 \%$ in the control group ${ }^{(14)}$.

The prevalence of epilepsy in CD is reported as 1\%-5\% and a 1.4-fold increased epilepsy risk was reported in CD patients in an epidemiologic study ${ }^{(15,18)}$. Although the exact cause is unknown; the cross reaction of Antigliadin antibodies with synapsin, gluten neurotoxicity or pyridoxine or folate deficiency are all suspected ${ }^{(5,7)}$.

In another study of us we have reported an increased prevalence of positive immunoglobulin A anti-tissue trans- glutaminase antibody with the diagnosis of childhood partial epilepsy with occipital paroxysms ${ }^{(12)}$. Similar with our results Dai et al. ${ }^{(6)}$ reported an increased prevalence of CD among the patients with occipital lobe epilepsy compared with the normal population. They also have reported that these seizures were uncontrollable through monotherapy ${ }^{(6)}$. However, Vieira et al. and Djuric et al. did not determine an association of CD with epilepsy in their studies ${ }^{(10,23)}$. Although ataxia, named as gluten ataxia, was reported as one of the most common neurological symptoms among CD patients, we have reported only two cases of ataxia in this study. Gluten ataxia is mainly reported in CD patients in their adult ages ${ }^{(4)}$. However, Kieslich et al. ${ }^{(13)}$ reported that two $(2.7 \%)$ cases had 'mild ataxia', in their study on 75 diet-treated CD patients with a mean age of 11.6 years.

Although the exact cause of neurological manifestations among CD patients is not clear; nutritional, immunologic and inflammatory effects of disease have been suspected. The immunologic pathways are also accused to be responsible for this relationship ${ }^{(17)}$. Autoimmunity resulting from molecular mimicry between gliadin and nervous system proteins has been proposed to play a role in neurological manifestations of celiac disease ${ }^{(1)}$.

An interesting finding of this study was the statistically significantly more common Marsh type $3 \mathrm{~b}$ biopsy findings among patients with neurological manifestations. Although, in a recent study, Aleksandra et al. (2) reported that Marsh $3 \mathrm{~b} / \mathrm{c}$ was more common in typical CD patient compared with the atypical presentations, the exact relationship between the histopathological changes and neurological manifestations of $\mathrm{CD}$ has not been studied before. However, since histological changes in celiac disease has a patchy distribution and duodenal lesions may vary among different biopsies ${ }^{(20)}$, this finding is dubious and should be confirmed with larger studies.

Of course there are some limitations of this study that should be mentioned. Mainly, we did not have a control group without celiac disease and we did not compare the prevalence of those neurological manifestations with an age-sex matched celiac-free group. Although this was a prospective study, we could not determine the effects of gluten free diet on neurological findings on follow-ups. Recently, vitamin E deficiency was suggested as a cause of some neurological findings in CD patients ${ }^{(19)}$ but we could not compare the vitamin E levels in this study. Although this is not a real weakness, it may be worthy also to compare the vitamin E levels between these two groups.

It is important to keep in mind that in clinical course of CD different neurological manifestations may be reported. On the other hand in the presence of different neurologic symptoms of unknown etiology and/or resistant to treatment, CD must be taken into account as an underlying disease. Larger prospective studies are warranted to determine the association of biopsy findings with the neurological face of celiac disease.

\section{Authors' contributions}

Işıkay $\mathrm{S}$ and Kocamaz $\mathrm{H}$ evaluated the patients and wrote the manuscript together. 
Işıkay S, Kocamaz H. A face neurológica da doença celíaca Arq Gastroenterol. 2015,52(3):167-70.

RESUMO - Contexto - Várias doenças neurológicas têm sido amplamente descritas em pacientes com doença celíaca. Objetivo - O objetivo deste estudo foi determinar a incidência de diferentes manifestações neurológicas em crianças com doença celíaca em acompanhamento no momento do diagnóstico e discutir essas manifestações à luz da literatura recente. Métodos - Este estudo seccional transversal prospectivo incluiu 297 crianças diagnosticadas com a doença celíaca. Os registros médicos de todos os pacientes foram revistos. Resultados - Na avaliação, 40 (13,5\%) dos 297 pacientes celíacos havia algum achado neurológico, incluindo dor de cabeça, epilepsia, enxaqueca, retardo mental, crises de perda de choro, ataxia, paralisia cerebral, síndrome de déficit de atenção e hiperatividade, e síndrome de Turner, em ordem de frequência. Não houve qualquer diferença significativa entre os dados laboratoriais de pacientes com e sem manifestações neurológicas. No entanto, biópsia tipo 3a foi, estatisticamente, significativamente mais comum entre os pacientes sem manifestações neurológicas, enquanto o tipo $3 \mathrm{~b}$ foi mais comum e estatisticamente significante entre os pacientes com manifestações neurológicas. Conclusão - É importante manter em mente que, no curso clínico da doença celíaca, diferentes manifestações neurológicas podem ser relatadas.

DESCRITORES - Doença celíaca. Manifestações neurológicas. Criança.

\section{REFERENCES}

1. Alaedini A, Okamoto H, Briani C, Wollenberg K, Shill HA, Bushara KO, et al Immune cross-reactivity in celiac disease: anti-gliadin antibodies bind to neuronal synapsin I. J Immunol. 2007;178(10):6590-5.

2. Aleksandra B, Ivana K, Ivica S, Prokic D. Profile of typical and atypical celiac disease in Serbian children. Indian Pediatr. 2013;50(11):1061-2.

3. Benjilali L, Zahlane M, Essaadouni L. A migraine as initial presentation of celiac disease. Rev Neurol (Paris). 2012;168(5):454-6.

4. Bushara KO. Neurologic presentation of celiac disease. Gastroenterology. 2005;128 (4 Suppl 1):92-7.

5. Canales P, Mery VP, Larrondo FJ, Bravo FL, Godoy J. Epilepsy and celiac disease: Favorable outcome with a gluten-free diet in a patient refractory to antiepileptic drugs. Neurologist. 2006;12(6):318-21.

6. Dai AI, Akcali A, Varan C, Demiryürek AT. Prevalence of resistant occipital lobe epilepsy associated with celiac disease in children. Childs Nerv Syst. 2014;30(6):1091-8.

7. Devinsky O, Schein A, Najjar S. Epilepsy associated with systemic autoimmune disorders. Epilepsy Curr. 2013;13(2):62-8.

8. Diaconu G, Burlea M, Grigore I, Anton DT, Trandafir LM. Celiac disease with neurologic manifestations in children. Rev Med Chir Soc Med Nat Iasi. 2013;117(1):88-94.

9. Dimitrova AK, Ungaro RC, Lebwohl B, Lewis SK, Tennyson CA, Green MW, et al. Prevalence of migraine in patients with celiac disease and inflammatory bowel disease. Headache. 2013;53(2):344-55.

10. Djurić Z, Nagorni A, Jocić-Jakubi B, Dimić M, Novak M, Milićević R, et al. Celiac disease prevalence in epileptic children from Serbia. Turk J Pediatr. 2012;54(3):247-50

11. Fasano A, Berti I, Gerarduzzi T, Not T, Colletti RB, Drago S, et al. Prevalence of celiac disease in at not-at-risk groups in the United States: a large multicenter study. Arch Intern Med. 2003;163(3):286-92.
12. Ișıkay S, Kocamaz H. Prevalence of celiac disease in children with idiopathic epilepsy in southeast Turkey. Pediatr Neurol. 2014;50(5):479-81.

13. Kieslich M, Erra'zuriz G, Posselt HG, Moeller-Hartmann W, Zanella F, Boehles $\mathrm{H}$. Brain whitematter lesions in celiac disease: a prospective study of 75 diet-treated patients. Pediatrics 2001;108(2):21.

14. Lionetti E, Francavilla R, Maiuri L, Ruggieri M, Spina M, Pavone P, et al. Headache in pediatric patients with celiac disease and its prevalence as a diagnostic clue. J Pediatr Gastroenterol Nutr 2009;49(2):202-7.

15. Ludvigsson JF, Zingone F, Tomson T, Ekbom A, Ciacci C. Increased risk of epilepsy in biopsy-verified celiac disease: A population-based cohort study. Neurology. 2012;78(18):1401-7.

16. Marsh MN. Gluten, major histocompatibility complex, and the small intestine. A molecular and immunobiologic approach to the spectrum of gluten sensitivity ('celiac sprue'). Gastroenterology 1992;102(1):330-54.

17. Muller AF, Donnelly MT, Smith CM, Grundman MJ, Holmes GK, Toghill PJ Neurological complications of celiac disease: a rare but continuing problem. Am J Gastroenterol. 1996;91(7):1430-5.

18. Pengiran Tengah DS, Holmes GK, Wills AJ. The prevalence of epilepsy in patients with celiac disease. Epilepsia. 2004;45(10):1291-3.

19. Pfeiffer RF. Neurologic manifestations of malabsorption syndromes. Handb Clin Neurol 2014;120:621-32.

20. Ravelli A, Villanacci V, Monfredini C, Martinazzi S, Grassi V, Manenti S. How patchy is patchy villous atrophy?: distribution pattern of histological lesions in the duodenum of children with celiac disease. Am J Gastroenterol. 2010;105(9):2103-10.

21. Rewers M. Epidemiology of celiac disease: what are the prevalence, incidence, and progression of celiac disease? Gastroenterology. 2005;128(4 Suppl 1):47-51

22. Shahriar Nikpour. Neurological manifestations, diagnosis, and treatment of celiac disease: A comprehensive review. Iran J Neurol 2012;11(2):59-64.

23. Vieira C, Jatobá I, Matos M, Diniz-Santos D, Silva LR. Prevalence of celiac disease in children with epilepsy. Arq Gastroenterol. 2013;50(4):290-6.

24. Zelnik N, Pacht A, Obeid R, Lerner A. Range of neurologic disorders in patients with celiac disease. Pediatrics. 2004;113(6):1672-6. 